\title{
Changes in Electrokinetic Coupling Coefficients of Granite under Triaxial Deformation
}

\author{
Osamu Kuwano and Shingo Yoshida \\ Earthquake Research Institute, University of Tokyo, 1-1-1 Yayoi, Bunkyo-ku, Tokyo 113-0032, Japan \\ Correspondence should be addressed to Osamu Kuwano, kuwano@eri.u-tokyo.ac.jp
}

Received 30 June 2011; Revised 21 September 2011; Accepted 29 October 2011

Academic Editor: Tsuneo Ishido

Copyright (C) 2012 O. Kuwano and S. Yoshida. This is an open access article distributed under the Creative Commons Attribution License, which permits unrestricted use, distribution, and reproduction in any medium, provided the original work is properly cited.

Electrokinetic phenomena are believed to be the most likely origin of electromagnetic signals preceding or accompanying earthquakes. The intensity of the source current due to the electrokinetic phenomena is determined by the fluid flux and the electrokinetic coupling coefficient called streaming current coefficient; therefore, how the coefficient changes before rupture is essential. Here, we show how the electrokinetic coefficients change during the rock deformation experiment up to failure. The streaming current coefficient did not increase before failure, but continued to decrease up to failure, which is explained in terms of the elastic closure of capillary. On the other hand, the streaming potential coefficient, which is the product of the streaming current coefficient and bulk resistivity of the rock, increased at the onset of dilatancy. It may be due to change in bulk resistivity. Our result indicates that the zeta potential of the newly created surface does not change so much from that of the preexisting fluid rock interface.

\section{Introduction}

Electrokinetic phenomena occur when an electrolyte flows along charged solid surfaces. For several decades, these phenomena have been of interest to geophysicists in many subfields. Observed self-potential has been associated with geothermal fields (e.g., $[1,2]$ ), volcanic activity and topography (e.g., [3-6]), and shallow ground water flow (e.g., $[7,8])$. In numerical modelings, quantitative interpretation of self-potential observed in geothermal and volcanic areas and modelings in hydrogeophysics have been studied (e.g., [9-13]). Electrokinetic phenomena are also believed to be the most likely origin of the observed electromagnetic signals preceding or accompanying earthquakes. Mizutani et al. [14] first proposed a model: during dilatancy stage, which is assumed to precede earthquakes $[15,16]$, pore pressure in the dilatant region decreases and water flows into this region from the surrounding area, generating electromagnetic precursors to earthquakes due to electrokinetic phenomena.

To provide an appropriate interpretation of field observations, a better understanding of the physics of electrokinetic effect at the level of the rock-fluid interface and at the level of the rock sample is required. In laboratory experiments, zeta potential and streaming potential coefficients, fundamental quantities that characterize the electrokinetic effect, were measured for crushed rocks (e.g., [5, 17-21]) and for natural intact rocks (e.g., [22-29]) to determine the electrokinetic parameters as a function of $\mathrm{pH}$, resistivity, permeability, or temperature. Jouniaux and Pozzi [23] measured the streaming potential coefficients of Fontainebleau sandstones under triaxial stress up to failure. They reported a large increase of the streaming potential coefficient beginning at about $75 \%$ of the yield stress. Yoshida [27] measured electric current and electric potential during rock deformation and found that the streaming current flowed before main failure, showing good correlation with dilatancy rate and water flow rate. In his study, however, changes of coupling coefficient (streaming potential coefficient or streaming current coefficient) during deformation were not measured.

Jouniaux and Pozzi [23] suggested that the increase of the streaming potential coefficient is due to an increase of zeta potential. An increase of the streaming potential coefficient, 
however, is also caused by an increase of bulk resistivity. In this study, by measuring not only the streaming potential coefficient but also the streaming current coefficient which has different dependence on bulk resistivity, we investigate what causes changes in the coupling coefficient during rock deformation.

\section{Electrokinetic Phenomena}

It is well known that when in contact with an electrolyte, the surface of rock-forming minerals are charged and surrounded by an equivalent amount of ionic charge of opposite sign from the electrolyte. The overall arrangement of the electric charge on the solid surface together with the balancing charge in the bulk liquid phase is often referred to as an electric double layer. Electrokinetic phenomena are induced by the relative motion between the fluid and the rock which develops an electric double layer. When the fluid in such a system moves due to a pressure gradient, the charges in the fluid are transported in the direction of fluid motion, resulting in an electric current. In a porous medium the electric current density $\mathbf{i}$ (in $\mathrm{A} / \mathrm{m}^{2}$ ) and fluid flux $\mathbf{j}$ (i.e., flow velocity, in $\mathrm{m} / \mathrm{s}$ ) are described by the following relations $[30,31]$ :

$$
\begin{gathered}
\mathbf{i}=-\frac{\sigma_{f}+\sigma_{s}}{F} \operatorname{grad} \phi+\frac{\epsilon \zeta}{\mu F} \operatorname{grad} P_{p}, \\
\mathbf{j}=\frac{\epsilon \zeta}{\mu F} \operatorname{grad} \phi-\frac{k}{\mu} \operatorname{grad} P_{p},
\end{gathered}
$$

where $\sigma_{f}$ and $\sigma_{s}$ are the electrical bulk and surface conductivities, $\epsilon$ is the dielectric constant of the fluid, $\zeta$ is the zeta potential (the potential at the slipping plane near the boundary), $k$ is the permeability, $\mu$ is the viscosity of the fluid, $P_{p}$ is the pressure of the fluid, and $\phi$ is the streaming potential. The first term of (1) represents Ohm's law, and the second term represents streaming current which can be derived by considering the product of the charge density (proportional to $\epsilon \zeta$ ) with the flow velocity of the viscous fluid (proportional to grad $P_{p} / \mu$ ). The first term of (1) shows the macroscopic conductivity of rock (reciprocal of bulkresistivity), which is expressed as

$$
\sigma_{R}=\frac{\sigma_{f}+\sigma_{s}}{F} .
$$

Considering the capillary model $[17,32]$, we define formation factor $F$ as

$$
F=\frac{\sigma_{\mathrm{eff}}}{\sigma_{R}}=\frac{T^{2}}{\eta}
$$

where $\eta$ is the porosity, $T$ is the tortuosity, and $\sigma_{\text {eff }}$ is the effective conductivity defined as

$$
\sigma_{\text {eff }}=\sigma_{f}+\sigma_{s}
$$

The surface conductivity $\sigma_{s}$ (in $\mathrm{S} / \mathrm{m}$ ) is related to the specific surface conductance $\Sigma_{s}$ (in S) by $\sigma_{s}=2 \Sigma_{s} / m$, where $m$ is hydraulic radius for the capillary model. The permeability of the capillary model is represented as

$$
k=\frac{\eta}{T^{2}} \frac{m^{2}}{b}
$$

where $b$ is a constant related to the shape of pore; $b=$ 8 for capillaries with a circular cross-section. We refer to $-\mathbf{i} / \operatorname{grad} P_{p}$ under $\operatorname{grad} \phi=0$ in (1) as the streaming current coefficient $C_{c}$ :

$$
C_{c}=\frac{\epsilon \zeta}{\mu F}=\frac{\eta}{T^{2}} \frac{\epsilon \zeta}{\mu} .
$$

Both $C_{c}$ and $k$ are functions of the fluid path network, and the dependence of $C_{c}$ and $k$ on $\eta$ and $T$ are the same. However, dependencies on $m$ are different for $C_{c}$ and $k$. The difference by $m^{2}$ can be understood if we note that the volume flow rate of a viscous fluid through a tube is proportional to the square of the cross-sectional area of the tube, while the amount of the transport electric charges distributed along the boundary are proportional to circumference length (i.e., proportional to the radius) and the flow velocity around the boundary is also proportional to the radius.

If there are no external current sources and no leaking current, the streaming current (due to $\operatorname{grad} P_{p}$ ) would be balanced by the conduction current (due to $\operatorname{grad} \phi$ ), so

$$
\Delta \phi=\frac{\epsilon \zeta}{\sigma_{\mathrm{eff}} \mu} \Delta P_{p},
$$

which is the Helmholtz-Smoluchowski equation. The ratio $\Delta \phi / \Delta P_{p}$ is referred to as the streaming potential coefficient,

$$
C_{p}=\frac{\Delta \phi}{\Delta P_{p}}=\frac{\epsilon \zeta}{\sigma_{\mathrm{eff}} \mu}=\frac{C_{c}}{\sigma_{\mathrm{eff}} / F}=\frac{C_{c}}{\sigma_{R}} .
$$

In general geometry, divergence of the total current is zero, but the zero total current condition (7) is not always satisfied.

\section{Experimental Methods}

In this study, we measured the streaming current (or streaming potential), permeability, and dilatancy of the rock specimen simultaneously and continuously during rock deformation test. We used the triaxial apparatus which was specially designed to investigate the electrical behavior during rock deformation and failure [27]. In this apparatus, the rock specimen is electrically isolated from the surroundings by inserting alumina plates. The pore fluid tubes of stainless steel inside the vessel are also isolated from the outside fluid tubes by using insulating tubes through the vessel closure as shown in Figure 1. This apparatus has two options for force loading: hydraulic loading with servo valves and a screwed pump with a servo motor. In the present experiment, we used the screwed pump for deformation test at a strain rate of approximately $10^{-7} / \mathrm{s}$. This apparatus is equipped with up to 11 feedthroughs that Nishizawa [33] developed on the basis of Bridgeman's self-sealing mechanism. During the 


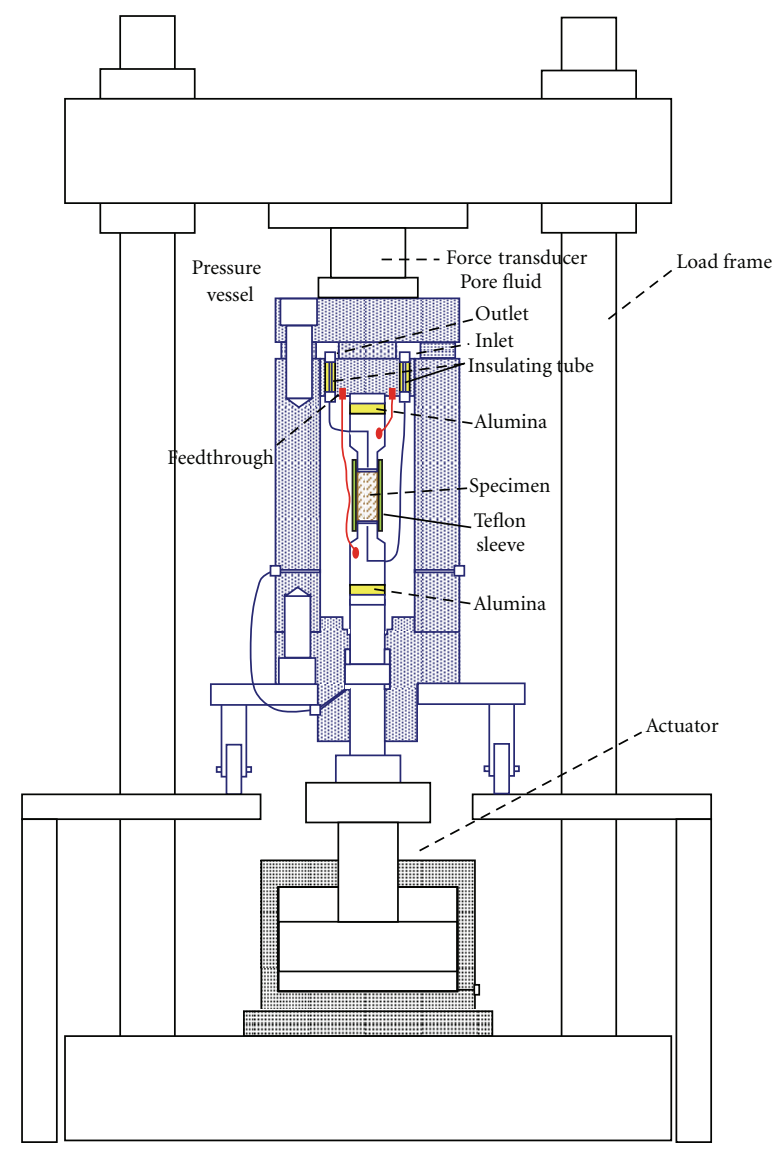

(a)

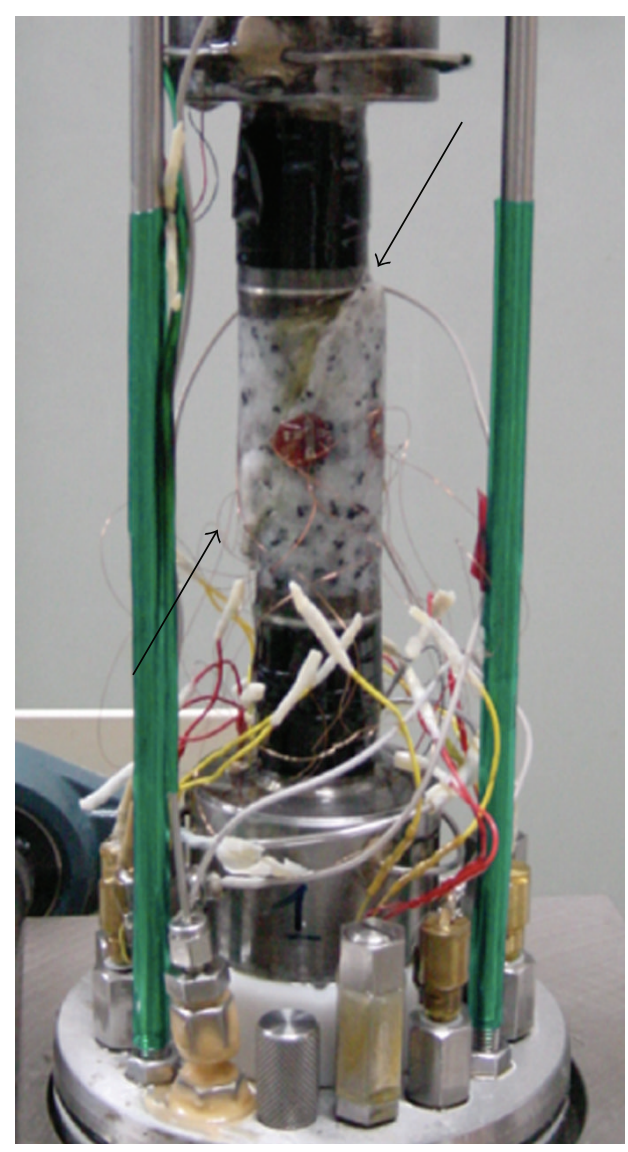

(b)

FIGURE 1: (a) Schematic diagram of apparatus. A rock specimen is electrically isolated by inserting alumina plates and by using insulating tubes of pore water through vessel closure. (b) Picture of the specimen after experiment. A failure plane is indicated by black arrows.

experiment, we measured differential axial stress, axial piston displacement, pore fluid volume, pore pressure change, electric signals (either current or potential), and local strains of the specimen, at a sampling rate of $10 \mathrm{~Hz}$.

In the present study, we usedcoarse grained Inada granite (from a locality in Ibaraki, Japan), which has been often used as a standard specimen in rock mechanics (e.g., [27, 29, $34]$ ). We used two specimens which were cored cylindrically $24 \mathrm{~mm}$ in diameter and $60 \mathrm{~mm}$ in length. One specimen was used in the electric potential measurement and denoted G01. The other was used in the electric current measurement and denoted G02. The porosity of both specimens was approximately $1 \%$. The rock specimens were air-dried and degassed under a vacuum for 12 hours before being saturated with $10^{-3} \mathrm{M} \mathrm{KCl}$ solution for 2 days. The conductivity of the fluid was $14 \mathrm{mS} / \mathrm{m}$. Then, the specimens were placed between the stainless steel end plugs and jacketed in a Teflon sleeve.

To measure the axial strain $e_{z}$ and the circumferential strain $e_{h}$, strain gauges were mounted at four positions on the cylindrical surface of the Teflon sleeve. A volume change of the specimen $\Delta \mathrm{Vol}$ is estimated as $\Delta \mathrm{Vol}=\operatorname{Vol}^{0}\left(\tilde{e_{z}}+2 \tilde{e_{h}}\right)$, where $\widetilde{e_{z}}$ and $\tilde{e_{h}}$ are averaged strains for four positions, and $\mathrm{Vol}^{0}$ is the initial volume of the specimen. The crosssection of the specimen is assumed to remain circular. This assumption is not satisfied when a fault plane is formed and large localized deformation occurs. A volume change due to dilatancy is obtained by subtracting elastic deformation from the volume change.

To measure the permeability continuously during the deformation experiments [35], we adopted the sinusoidal oscillation method [36-39]. The method is based on the measurement of an attenuation and a phase retardation of an oscillation of the pore-fluid pressure as it propagates through the specimen. In its application, a sinusoidal pressure oscillation is imposed at one end of the specimen and a pressure response is monitored at the other end as illustrated in Figure 2. The permeability is calculated from the measured attenuation factor $R$ between downstream and upstream pore-fluid-pressure sinusoidal waves, and the phase lag $\delta$, using the following relation (calculations detailed in [37]),

$$
\begin{gathered}
P_{p 1}=R P_{p 2} \sin (\omega t-\delta) \\
R \cdot \exp (i \delta)=\frac{1}{\cosh [\psi(1+i)]+\gamma \psi(1+i) \sinh [\psi(1+i)]},
\end{gathered}
$$

where $P_{p 1}$ and $P_{p 2}$ are upstream and downstream pore fluid pressure, respectively, $R$ is the attenuation factor, $\delta$ is the 


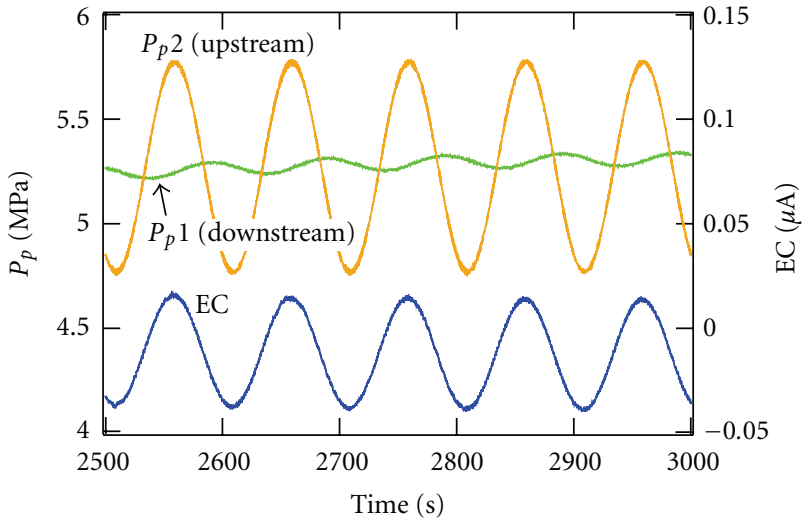

Figure 2: An example of measurement using the sinusoidal oscillation method. Upstream and downstream fluid pressure are shown as orange and green lines, respectively. In this example, electric current measured using stainless-steel end plugs equipped at each end of specimen as electrode is also shown (blue line). The streaming current coefficient is calculated from the amplitude of fluid-pressure difference $\left(P_{p 1}-P_{p 2}\right)$ and the amplitude of the electric current.

phase lag, $\omega$ is an angular frequency, and $i$ is the imaginary unit. From the measurements of $R$ and $\delta$, the value of dimensionless parameters $\psi$ and $\gamma$ can be evaluated, and then we obtain permeability $k$,

$$
k=\frac{\pi \mu f B_{d} L}{A \psi^{2} \gamma},
$$

where $f$ is a frequency of oscillation, $A$ is the cross-sectional area, $L$ is the length of the specimen, and $B_{d}$ is the storage of the downstream reservoir $\left(B_{d}=0.0038 \mathrm{~cm}^{3} / \mathrm{MPa}\right.$ in our apparatus). During the experiments, the upstream porefluid pressure $\left(P_{p 2}\right)$ was sinusoidally oscillated at a frequency of $0.01 \mathrm{~Hz}$ by computer-controlled servo-mechanism. The amplitude of the sinusoidal pressure variation was $0.5 \mathrm{MPa}$. The upper specimen face is connected to the downstream reservoir of a volume of $9.52 \mathrm{~cm}^{3}$. To calculate the permeability from the measured attenuation factor and phase lag, we used a custom-made code following Takahashi [35].

To reveal the physical mechanism causing the observed changes of electrokinetic properties of rock-water system, it is convenient to measure both of the two coupling coefficients, namely, the streaming potential coefficient and the streaming current coefficient, because the streaming potential coefficient involves bulk resistivity and the source current. We measured electric current or potential between the upper and bottom faces of the specimen with an electrometer (Keithley 6517) by using the stainless-steel end plugs placed at the both ends of the specimen as electrodes. Electric potential was measured in the experiment using specimen G01 and electric current was measured in another experiment using specimen G02, respectively, because an electric potential and an electric current could not be measured at the same time. The sinusoidal oscillation method [29] enables us to measure the streaming potential (or current) induced by pore-fluid movement continuously during a rock deformation test. Figure 2 shows a typical data obtained by the oscillation test at a frequency of $0.01 \mathrm{~Hz}$. The resultant electric current showed sinusoidal variations. By reading the amplitude of the sinusoidal variation of the electric current $\left(\Delta I_{s}\right)$ and the amplitude of the sinusoidal variation of the fluid pressure difference $\left(\Delta P_{p}=P_{p 1}-P_{p 2}\right)$, we evaluated the generated current per unit change in the fluid pressure $\Delta I_{s} / \Delta P_{p}$. The streaming current coefficient $C_{\mathrm{c}}$ was obtained using the relation

$$
C_{c}=\frac{\Delta I_{s} / S}{\Delta P / L}=\frac{\Delta I_{s}}{\Delta P} \frac{L}{S}[\mathrm{~A} / \mathrm{mMPa}]
$$

Similarly, from measurements of the amplitude of electric potential variation $(\Delta \phi)$, we estimated the streaming potential coefficient as

$$
C_{p}=\frac{\Delta \phi}{\Delta P_{p}}[\mathrm{~V} / \mathrm{MPa}]
$$

Frequency effect on the coupling coefficient [40-42] for the Inada granite with the present experiment system has been reported in [27]. Coupling coefficient does not depend on frequency in such a low frequency range $(0.01-1 \mathrm{~Hz})$ for the intact Inada granite. Although we cannot rule out the possibility of the changes of frequency dependence on the coupling coefficient during deformation, we focus on the continuous measurement during deformation to fix the frequency to $0.01 \mathrm{~Hz}$ and do not discuss the frequency dependence in the present study.

\section{Results}

Here, we show the results of the two experiments. Experimental conditions for G01 and G02 were the same. The confining pressure $P_{c}$ was kept at $15 \mathrm{MPa}$. The pore-fluid pressure at each end of the specimen was set to $5.3 \mathrm{MPa}$ at the beginning of the experiment. Then, pore fluid pressure of the bottom face of the specimen was sinusoidally oscillated

at a frequency of $0.01 \mathrm{~Hz}$ with an amplitude of $0.5 \mathrm{MPa}$ throughout the rest of the experiment. Experiments were conducted under room temperature $\left(25 \pm 1^{\circ} \mathrm{C}\right)$.

Figure 3 shows the results of the run G01, in which electric potential was monitored. The axial loading rate was $5.1 \times 10^{-7} / \mathrm{s}$. A shear failure plane was found in the postexperimental sample (Figure 1(b)). From Figure 3(a) showing the differential axial stress and the displacement, it can be seen that dynamic failure occurred at $t=37,323 \mathrm{~s}$. Some small releases of axial stress occurred around $t=$ 6,000 and $17,000 \mathrm{~s}$. These small stress releases may be due to poor initial setting of the apparatus. Thus, we do not analyze the data before these stress changes $(t \sim$ $20,000 \mathrm{~s})$. The pore-fluid pressure $P_{p 1}$ and $P_{p 2}$ are shown in Figure 3(b). The pore-fluid pressure of the bottom face of the specimen appears to be a thick line in this scale because it is sinusoidally oscillated at a frequency of $0.01 \mathrm{~Hz}$ and amplitude of 0.5 $\mathrm{MPa}$. Figure 3(e) shows the volume change of the specimen obtained from strain measurements and the dilatancy calculated by subtracting the elastic deformation from the volume change. In Figure 3(b), the volume change 


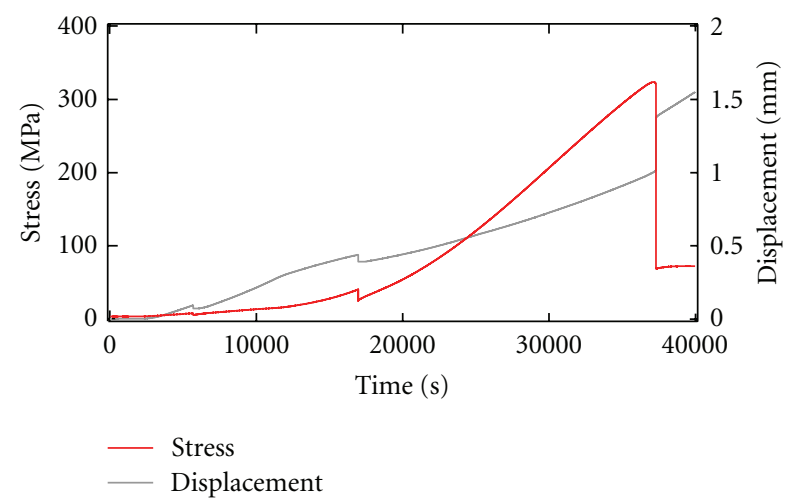

(a)

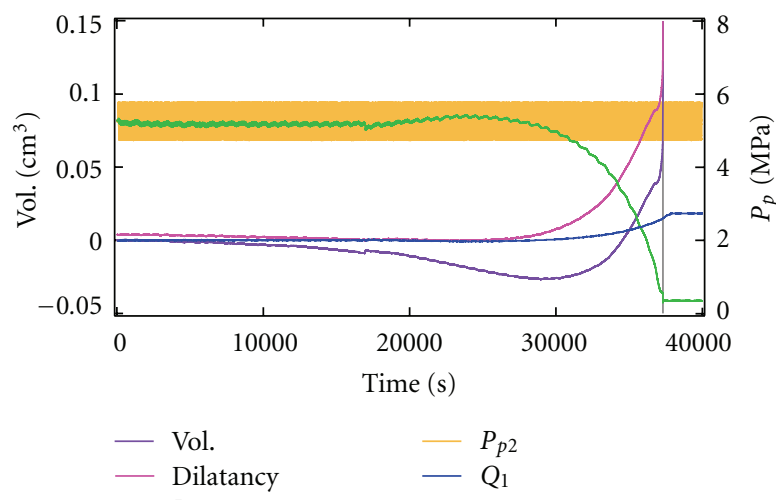

(b)

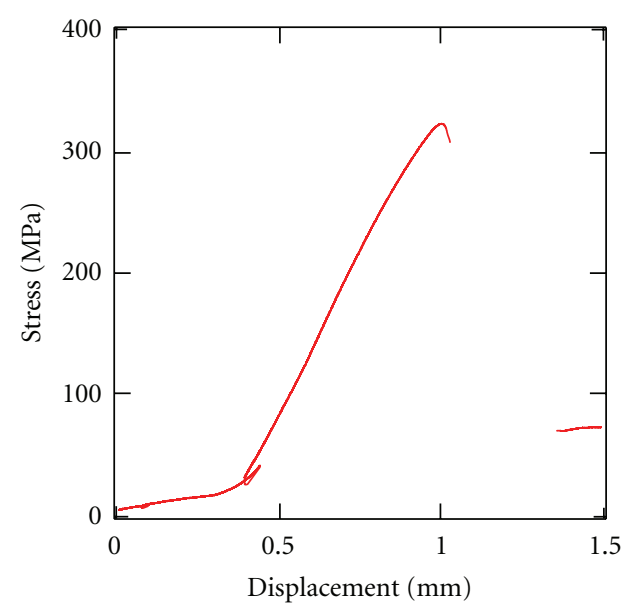

(d)

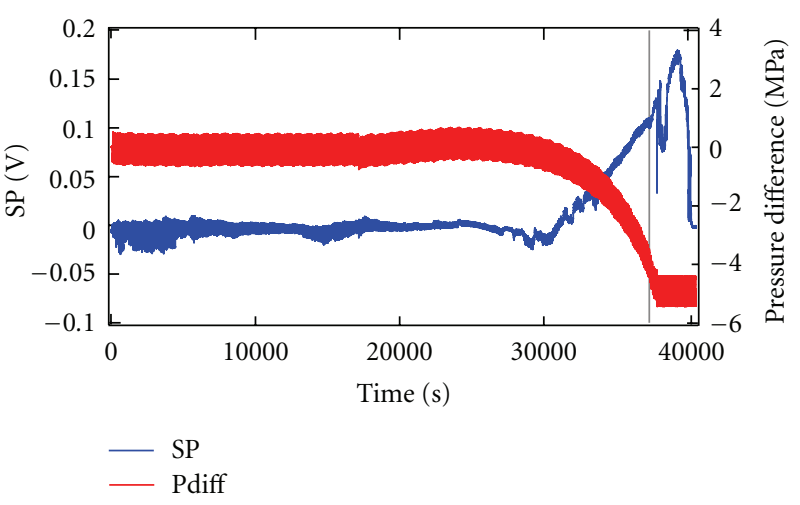

(c)

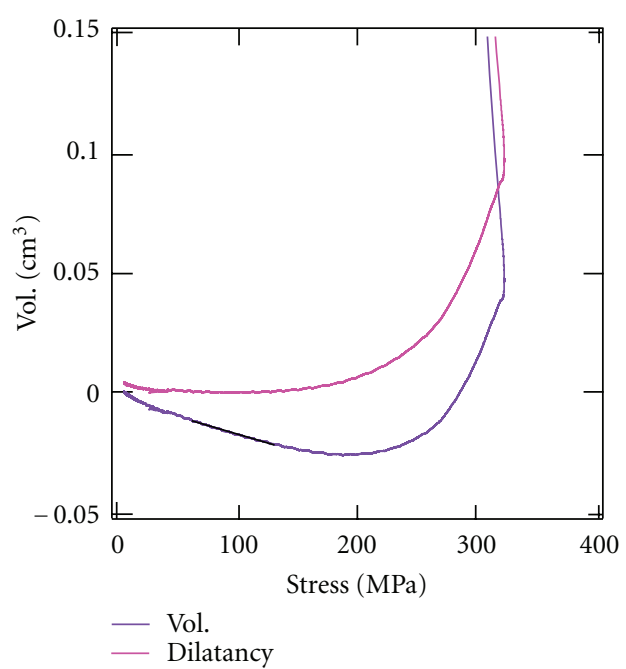

(e)

FIgure 3: Result of deformation test for initially intact Inada granite (G01) at $P_{c}=15 \mathrm{MPa}, P_{p}=5 \mathrm{MPa}$. (a) Differential stress and displacement. (b) Volume change of the specimen obtained from the average of the strain measurements at four positions, dilatancy, pore fluid pressures, and water volume. (c) Streaming potential (SP) and pore-fluid pressure difference between bottom and top faces of the specimen. (d) Axial stress versus axial displacement. In this experiment, failure stress was $324 \mathrm{MPa}$ and Young's modulus was $32 \mathrm{MPa}$. (e) Volume change of the specimen and dilatancy versus the axial stress. The elastic deformation is indicated by the thick black line in this figure. 


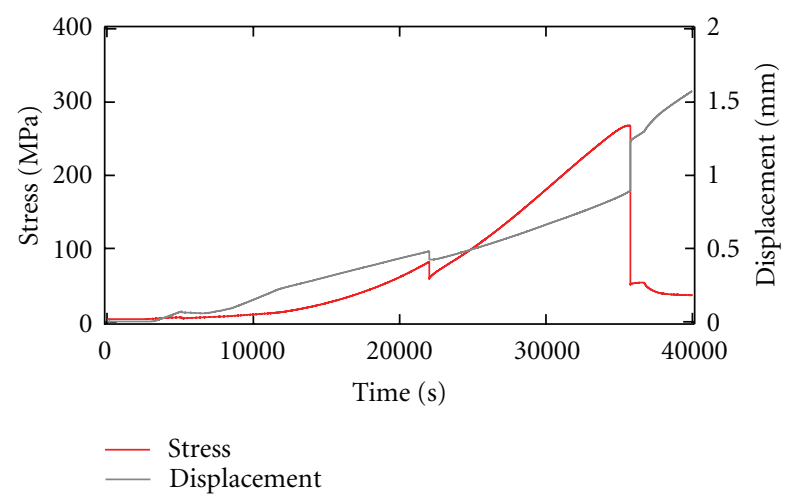

(a)

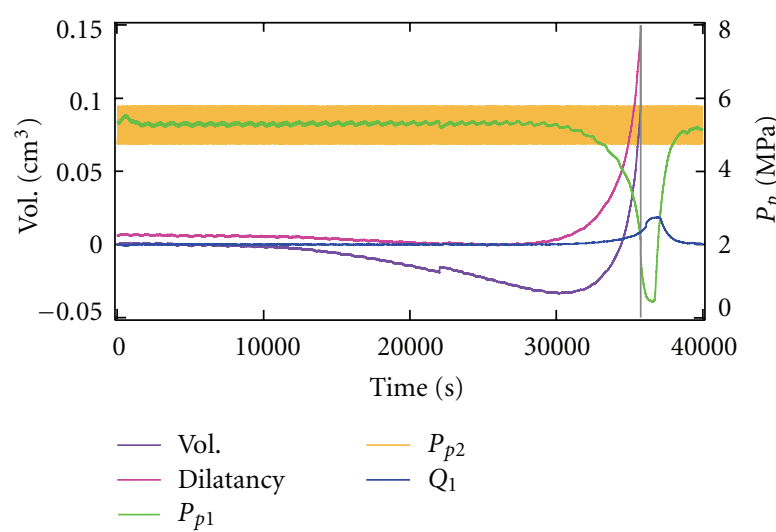

(b)

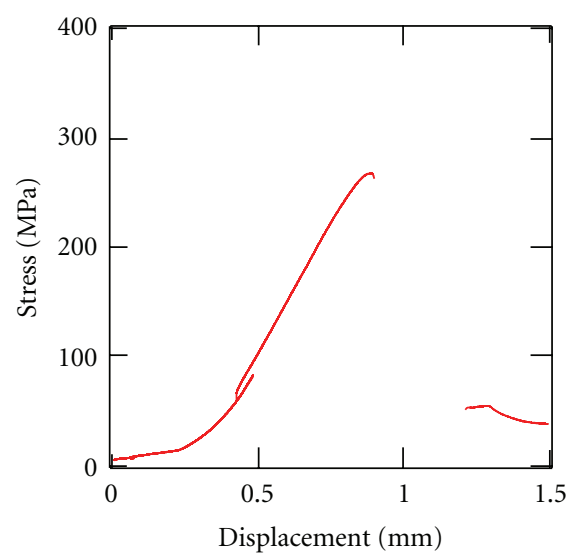

(d)

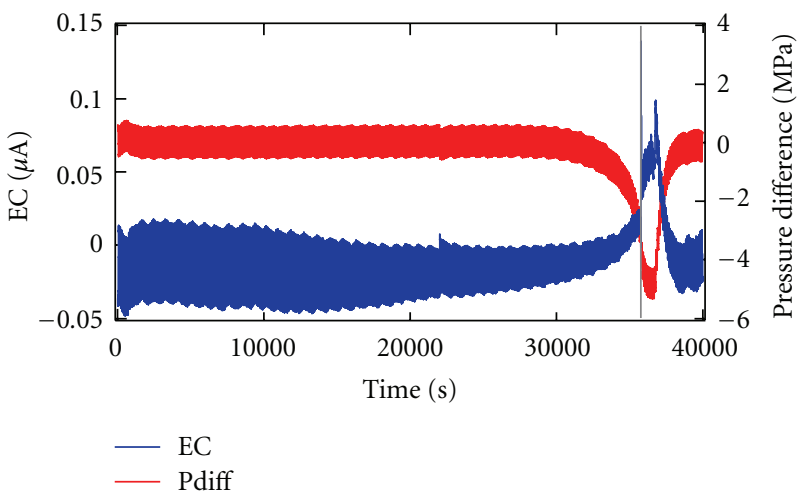

(c)

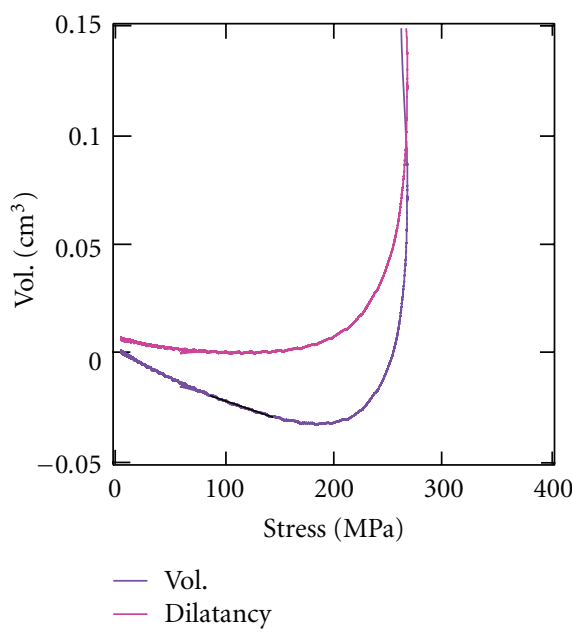

(e)

Figure 4: Result of deformation test for initially intact Inada granite (G02) at $P_{c}=15 \mathrm{MPa}, P_{p}=5 \mathrm{MPa}$. In this experiment, streaming current was measured instead of potential. This result also shows good correlation between the pressure difference and the streaming current. Failure stress was $268 \mathrm{MPa}$ and Young's modulus was $29 \mathrm{MPa}$.

and the dilatancy are plotted. When dilatancy began (around $t=27,000 \mathrm{~s}$ ), the downstream pore pressure $P_{p 1}$ began to drop, indicating that the pore pressure in the specimen dropped and water flowed into the specimen. From the change of $P_{p 1}$, we calculated the water volume $Q_{1}$, which flows into the specimen from the downstream reservoir, as $Q_{1}=-B_{d}\left(P_{p 1}-P_{p 0}\right)$, where $P_{p 0}$ is an initial pore pressure. Although we attempted to estimate the water volume $Q_{2}$, which flows into the specimen from the upstream side, using the displacement of the piston of the pore water 


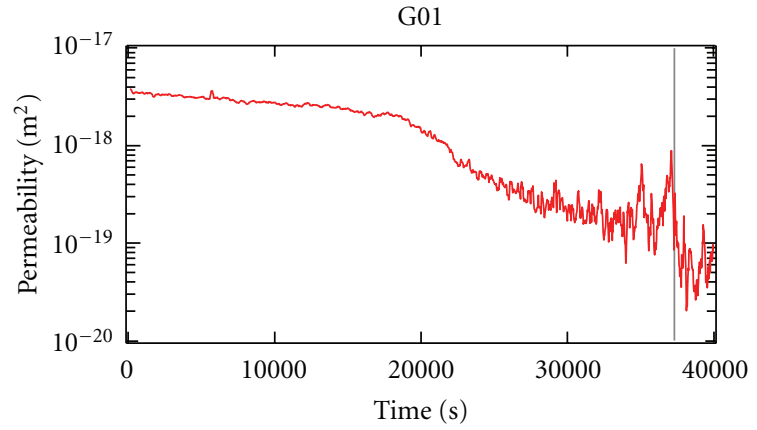

(a)

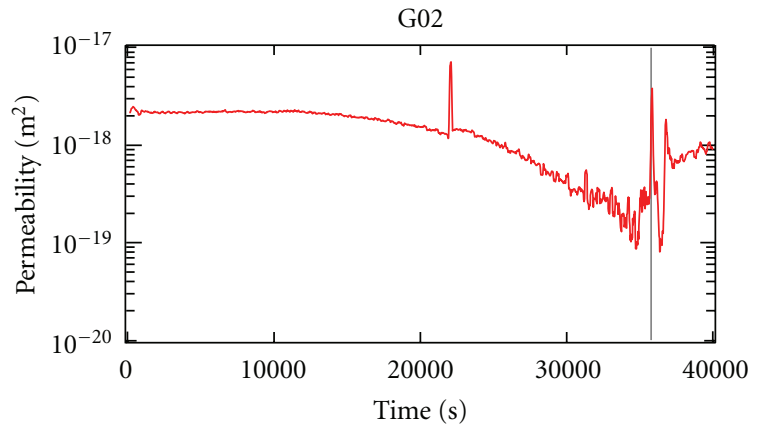

(b)

Figure 5: Permeability calculated from measured amplitude ratio and phase rag between upstream and downstream pore pressure $\left(P_{p 2}\right.$, $\left.P_{p 1}\right)$. Vertical gray lines indicate the time of failure.

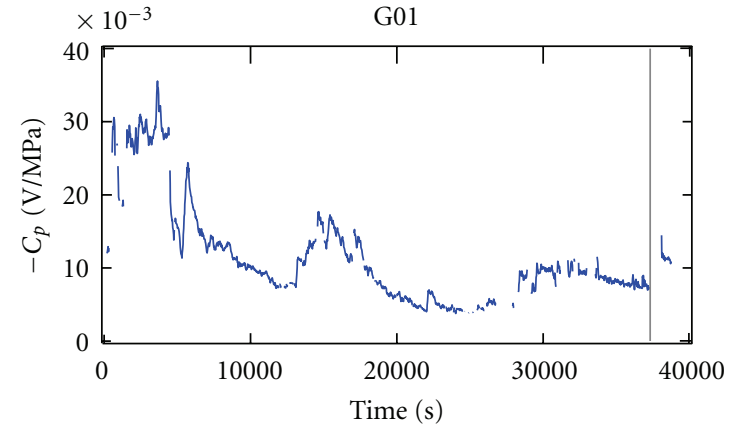

(a)

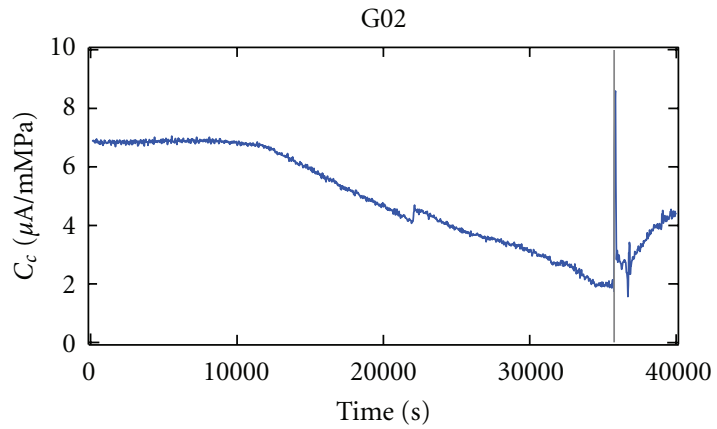

(b)

Figure 6: Coupling coefficients, $C_{p}(\mathrm{G} 01)$ and $C_{c}$ (G02), calculated from measured amplitude ratio of potential (or current) to pore pressure difference. Vertical gray lines indicate the time of failure.

intensifier, we could not estimate $Q_{2}$ due to the leakage of the water at the upstream side. Therefore, we show only $Q_{1}$ in Figure 3(b). In Figures 3(b) and 3(c), we can see good correlation among the trends of dilatancy, the pore pressure difference, and the streaming potential (SP). Details of this "DC" relation are discussed later. Here, we focus on the results of "AC" measurement based on the imposed sinusoidal oscillation of the pore pressure.

Figure 4 shows the other run (G02) in which the electric current was measured. A similar result with the run G01 was obtained, showing good correlation among dilatancy, pore pressure difference, and the streaming current (EC). The axial loading rate was $5.5 \times 10^{-7} / \mathrm{s}$. As in G01, a discrete shear plane was found in the postexperimental sample, indicating that the main failure (around $t=35,788 \mathrm{~s}$ ) involved the formation of such a failure plane. When dilatancy began (around $t=28,650 \mathrm{~s}$ ), the pore pressure of the downstream $P_{p 1}$ began to decrease. Some small stress releases were also observed at about $t=6,000$ and $22,000 \mathrm{~s}$ due to the setting of the apparatus similarly to the former experiment.

Figure 5 shows the permeability of G01 and G02. The permeability was initially of the order of $10^{-18} \mathrm{~m}^{2}$. With the increase of the axial loading, the permeability decreased to $10^{-19} \mathrm{~m}^{2}$. Then, just before the failure, the permeability increased to $\sim 10^{-18} \mathrm{~m}^{2}$ in the both experiments. There are a lot of studies dealing with permeability-porosity relationship and permeability-stress relationship (e.g., [43-45]). In our experiment, permeability reduction is approximately an exponential function of effective mean stress [45] and mainly attributed to elastic crack closure [43]. The permeability increase indicates enhanced connection of cracks. Although the dilatancy should involve the creation of microcracks, the permeability continued to decrease with progressive loading, indicating that microcracks were not fully interconnected or not fully saturated with pore fluid.

\section{Discussion}

The coupling coefficients $C_{p}$ (or $C_{c}$ ) were calculated from amplitude of pore pressure difference and potential (or current). The polarity of obtained coupling coefficients were negative in the present experiments, indicating negative zeta potential, as expected for granites. The values of the coupling coefficients are shown in absolute values hereafter. Figure 6 shows the coupling coefficients of G01 and G02. To remove the data which are not suitable for calculating streaming potential coefficient, we evaluated a signal quality by $P(0.01 \mathrm{~Hz}) / \sum P(f)$, where $P(f)$ is the power spectrum of potential variation. The data with the signal quality lower than 0.98 were not used. We can see variations of $C_{p}$ around 


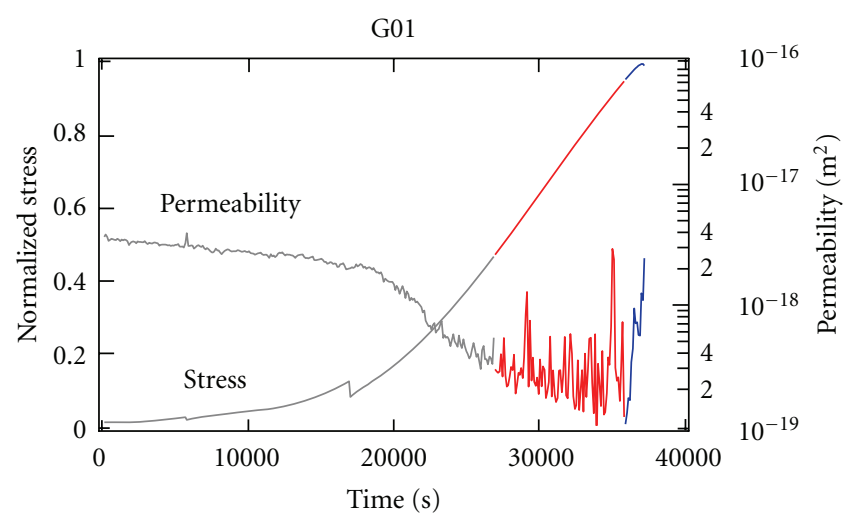

(a)

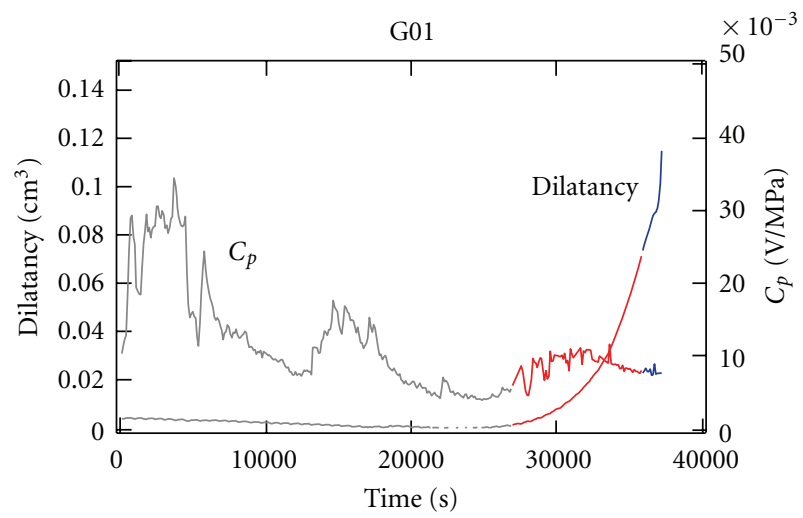

(c)

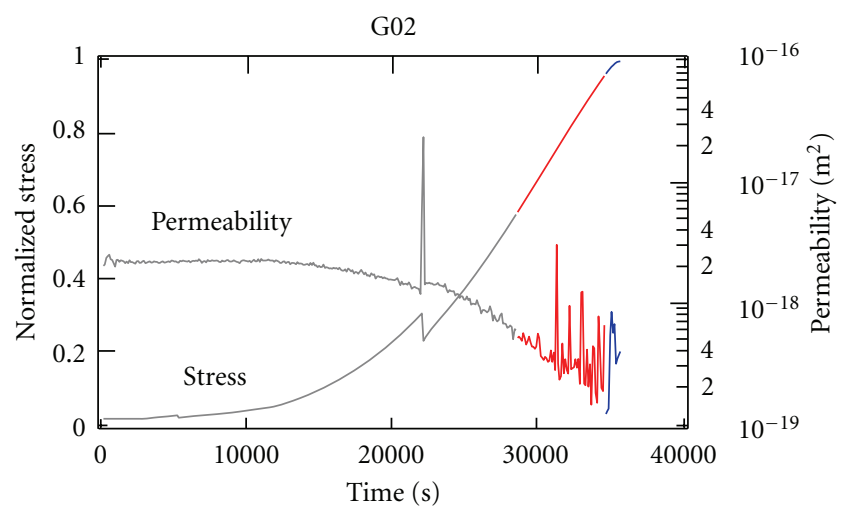

(b)

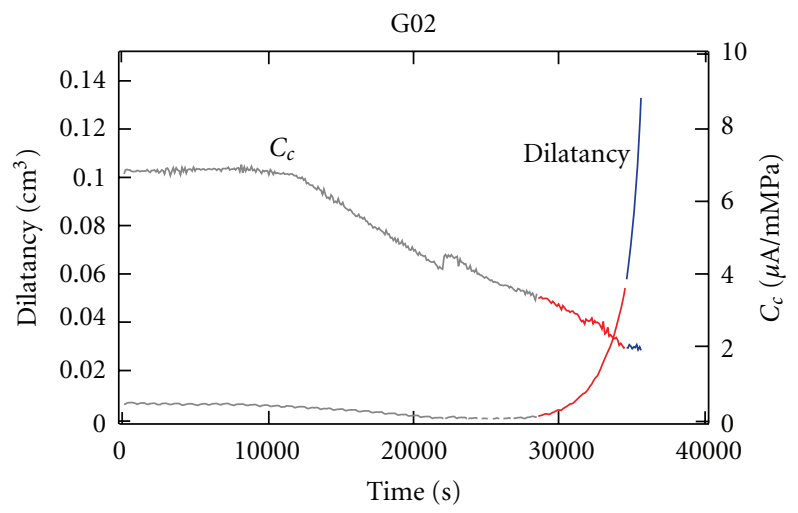

(d)

FIGURE 7: Normalized stress, permeability, dilatancy, and coupling coefficient versus time. The gray, red, and blue lines indicate the stages A, $\mathrm{B}$, and $\mathrm{C}$, respectively. Three stages which are divided by the beginning of dilatancy (G01 $t=27,000 \mathrm{~s}, \mathrm{G} 02 t=28,650 \mathrm{~s})$ and the beginning of permeability increase (G01 $t=36,000 \mathrm{~s}, \mathrm{G} 02 t=34,750 \mathrm{~s})$.

$t=6,000$ and 17,000 s in Figure 6(b). These variations were due to small stress releases resulting from the setting of the apparatus as mentioned before. A fluctuation of $C_{c}$ around $t=22,000 \mathrm{~s}$ was due to the same reason. The streaming potential coefficient $C_{p}$ decreased with loading (Figure 6) and then increased by a factor of two at the onset of dilatancy (around $t=27,000 \mathrm{~s}$ ). Note that $C_{p}$ did not continue to increase with dilatancy increase but $C_{p}$ increased just at the onset of the dilatancy. In contrast, the streaming current coefficient $C_{c}$ continued to decrease during the loading until the time of failure, not particularly affected by dilatancy. It is noted that the observed change in $C_{c}$ indicates that the source current density did not increase during the deformation, and therefore observed increase in $C_{p}$ is attributed to bulk resistivity (see (8)).

The estimation of the zeta potential is done from the measured streaming current coefficient. The streaming current coefficient $C_{c}$ of Inada granite before loading is approximately $7 \mu \mathrm{A} / \mathrm{mMPa}$. The formation factor $F$ of Inada granite under atmospheric pressure was estimated to be 1100 from the measurement of the resistance of the rock sample saturated with $\mathrm{KCl}$ solution with a high conductivity $(0.2-$ $1.1 \mathrm{~S} / \mathrm{m})$. Inserting these values into (6), we obtained the zeta potential as $-11 \mathrm{mV}$, which is slightly smaller than the previously reported value of granite $[17,18,29]$.
To investigate the evolution of the coupling coefficients in detail, we divide experiments into three stages; stage A: from the start of experiment to the beginning of dilatancy, stage B: from the beginning of dilatancy to the beginning of permeability increase, stage C: from the beginning of permeability increase to the failure. Figure 7 indicates these stages in different colors. We defined the normalized stress as the stress normalized by the failure stress. Figure $8(a)$ shows the streaming potential coefficient $C_{p}$ and the dilatancy of G01 as a function of the normalized stress. We can see that the dilatancy and increase of streaming potential coefficient began at $47 \%$ of yield stress. Figure 8 (b) shows the relation between the streaming potential coefficient and the dilatancy. Increase of the streaming potential coefficient $(5 \mathrm{~V} / \mathrm{MPa}$ to $10 \mathrm{~V} / \mathrm{MPa}$ ) occurred at the onset of the dilatancy. Figure 8(c) shows $C_{c}$ and the dilatancy of $\mathrm{G} 02$ as a function of the normalized stress. We can see the dilatancy began at $58 \%$ of the failure stress. The streaming current coefficient $C_{c}$ continued to decrease at an approximately constant rate unrelated to the dilatancy. Relation between the $C_{c}$ and the dilatancy is shown in Figure 8(d). When the permeability increase (stage C) began, $C_{c}$ stopped to decrease and remained roughly constant during the stage $\mathrm{C}$ up to failure.

Figure 9 shows the relation between the streaming current coefficients and the permeability. The streaming current 


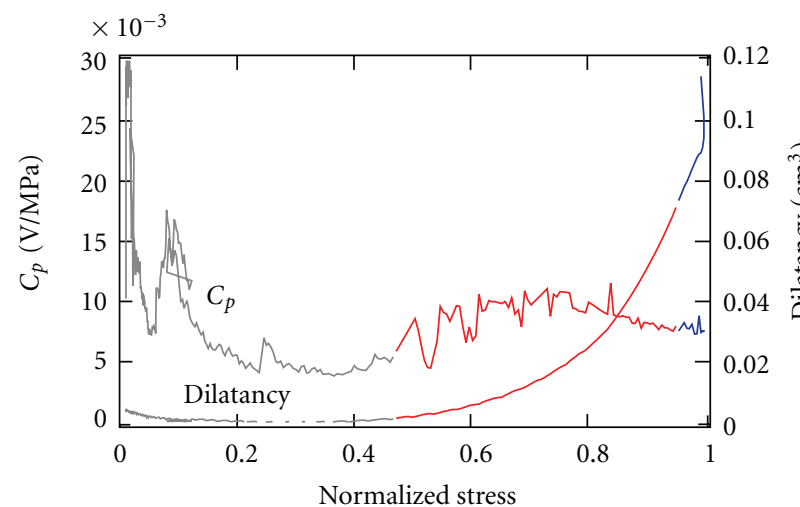

(a)

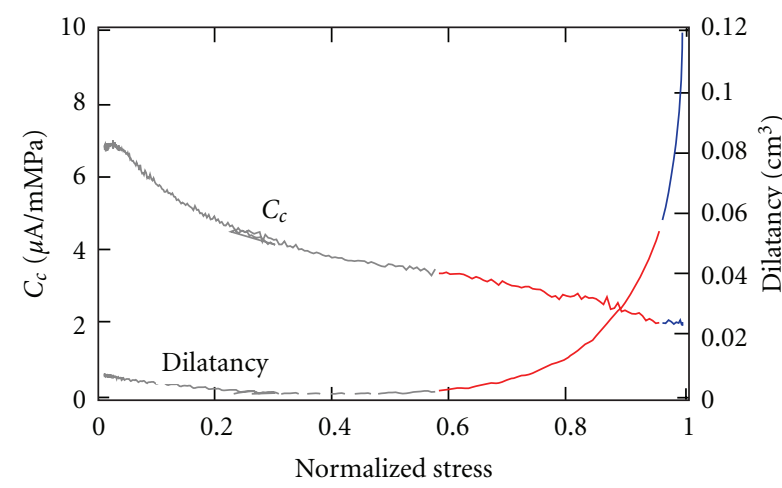

(c)

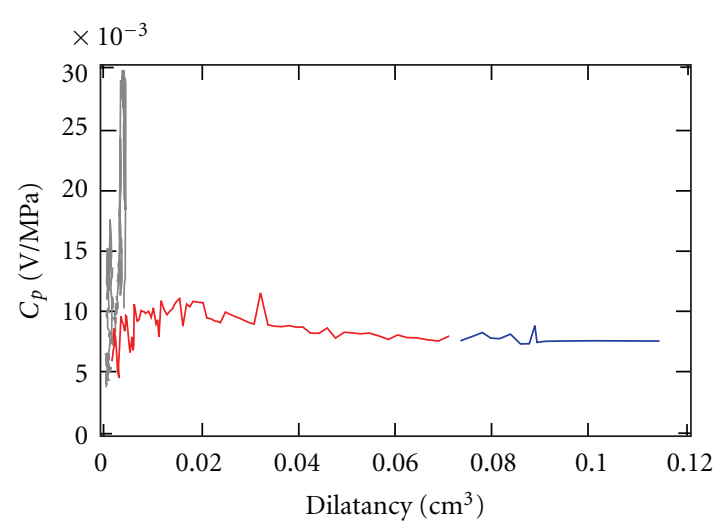

(b)

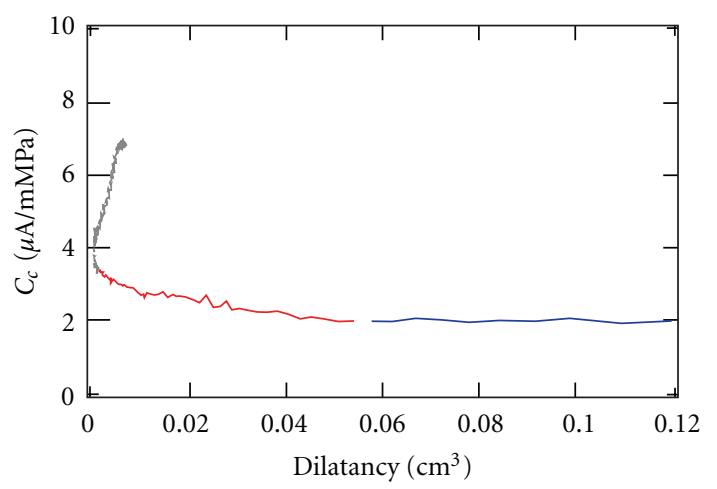

(d)

Figure 8: (a) $C_{p}$ and dilatancy versus normalized stress. (b) $C_{p}$ versus dilatancy. (c) $C_{c}$ and dilatancy versus normalized stress. (d) $C_{c}$ versus dilatancy.

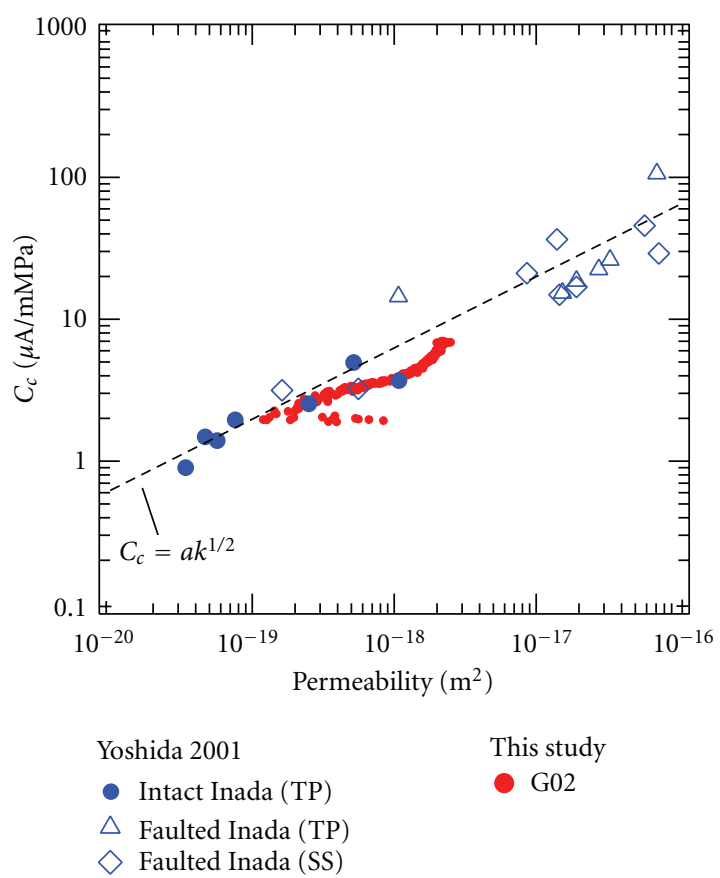

Figure 9: The streaming current coefficients $C_{c}$ as a function of the permeability. Blue symbols are data of Inada granite obtained by Yoshida [27]. coefficient $C_{c}$ was approximately proportional to the square root of the permeability. This dependence can be explained by assuming that $m^{2}$ is proportional to $1 / F=\eta / T^{2}$ in (5) and (6) for the capillary model [17, 27, 32]. This assumption is supported by the experimental results that $\log k$ is linearly related to $\log F$ with slope of $\sim-2$ for granite reported by Walsh and Brace [32].

The fact that the streaming current coefficient did not increase indicates that the zeta potential did not increase throughout the deformation test. Furthermore, there is a possibility of decrease of the zeta potential, because $C_{c}$ does not increase with the permeability increase in stage C. If bulk resistivity increases at the onset of the dilatancy, the streaming potential coefficient $C_{p}$, which is the product of $C_{c}$ and bulk resistivity (see (8)), will increase. Figures 3 (b) and 4(b) show the volume of water flow from the downstream $Q_{1}$, which is much smaller than dilatancy. The ratio of $Q_{1}$ to dilatancy is approximately 0.1 to 0.2 , indicating the possibility of the undersaturation of the pore, although the water flow from the upstream is not included. We mention the possibility of bulk-resistivity change here. To understand the observed change of $C_{p}$, we would require measurements of the bulk-resistivity changes during the deformation. On the basis of recent studies (e.g., [46-48]), however, the magnitude of $C_{p}$ decreases with decreasing water saturation $S_{w}$ in most situations even though substantial increase of bulk-resistivity takes place at the same time. 


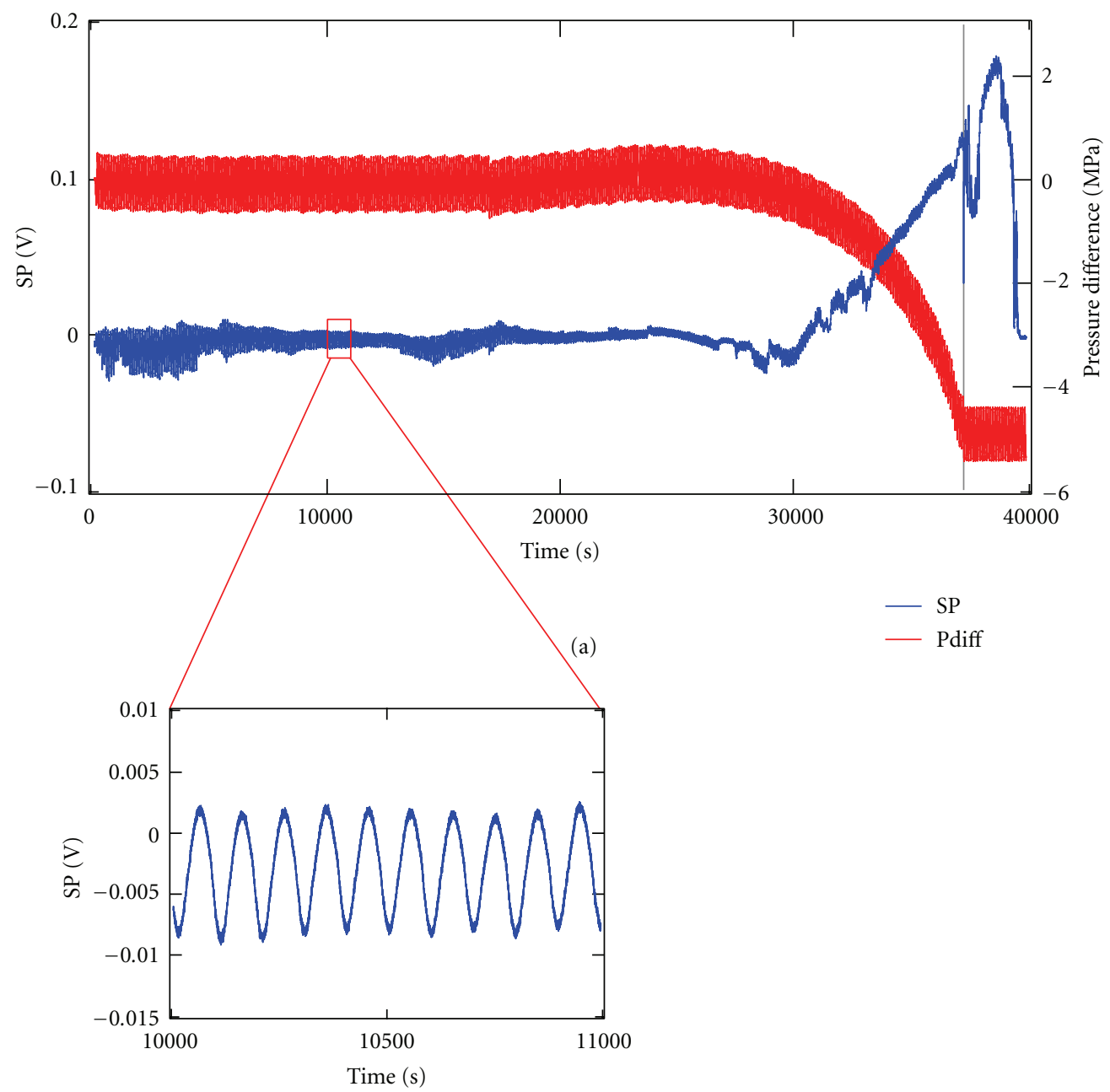

(b)

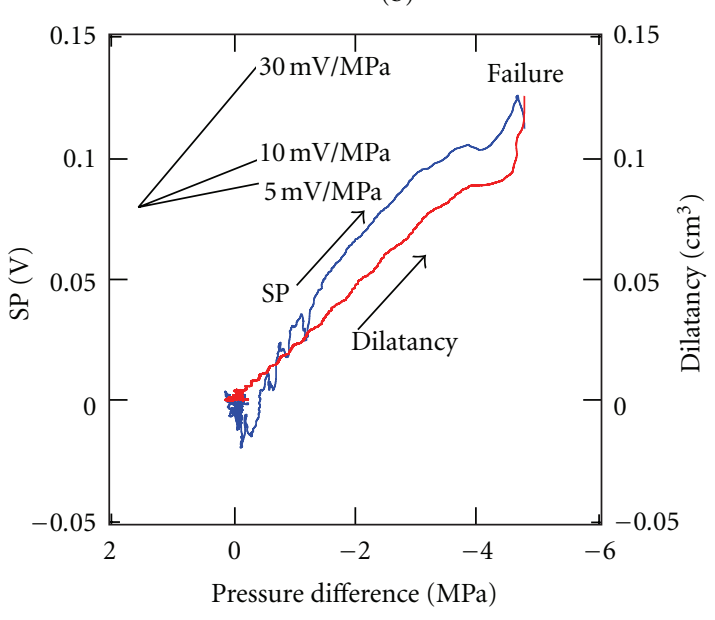

(c)

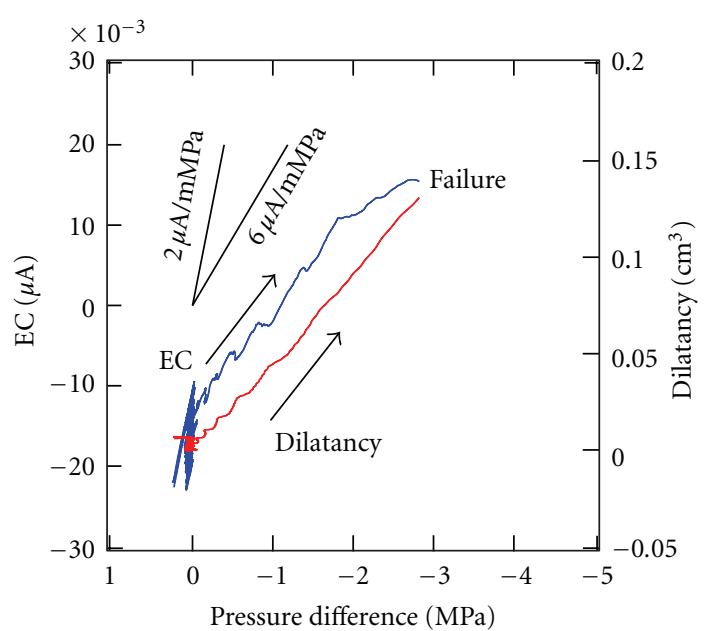

(d)

FIGURE 10: The streaming potential (SP) and the pore pressure difference (Pdiff). Long-term trend of these values are used in the "DC" measurements of electrokinetic phenomena (a). Amplitude and phase of the sinusoidal variation caused by imposed pore pressure oscillation are used for the "AC" measurements of electrokinetic phenomena (b). The DC coupling coefficients and the dilatancy as a function of the pressure difference for G01 (c) and G02 (d). Blue and red lines indicate coupling coefficients and dilatancy, respectively. 
The $S_{w}$ dependence of the coupling coefficients is important also for modeling of field self-potential data related to unsaturated flow in volcanic areas (e.g., $[49,50])$ and shallow groundwater systems. We need further study to clarify the $S_{w}$ change during dilatancy stage and its effect on the coupling coefficients of low-permeability rocks such as granite used in this study.

Here we compare the coupling coefficients obtained from the $\mathrm{AC}$ measurements and those obtained from the DC measurements. We can see the DC electrokinetic effect in Figure 10(a). Figure 10(b) shows the AC electrokinetic effect discussed earlier. The DC coupling coefficients and the dilatancy are shown as a function of the pressure difference in Figures 10(c), 10(d). The dilatancy showed a linear relation with the pressure difference in both experiments. The magnitude of the DC streaming current coefficient $C_{c}$ was approximately $6 \mu \mathrm{A} / \mathrm{mMPa}$ before dilatancy began and then decreased to $2 \mu \mathrm{A} / \mathrm{mMPa}$ after dilatancy began. These values agree well with the $C_{c}$ obtained from the AC measurement (see Figure 7). On the other hand, the magnitude of the DC streaming potential coefficient $C_{p}$ during dilatancy was approximately $30 \mathrm{mV} / \mathrm{MPa}$, which was three-times as large as that from the AC measurement (see Figure 7). At the present stage, we do not fully understand the discrepancy between AC and DC streaming potential coefficients. We need further study including a frequency dependence of the specific resistivity of the rock specimen.

\section{Conclusions}

Jouniaux and Pozzi [23] suggested that the onset of increase in the streaming potential coefficient corresponded to the onset of shear localization and that this increase was due to an increase of the zeta potential in the shear zone as new surfaces were created and connected. Although Jouniaux and Pozzi [23] suggested a possibility of the enhancement in the zeta potential on the newly created surface, there exists some uncertainties. They measured the streaming potential, which was the product of the streaming current density and the specific resistivity of the specimen. Therefore, one cannot deny a possibility that the observed increase of the streaming potential was due to an increased bulk resistivity rather than an enhanced zeta potential.

In our experiment, the $C_{p}$ increased but the $C_{c}$ did not increase, indicating that the source current density did not increase during the deformation. Such an increase in $C_{p}$ due to increase in bulk resistivity cannot be the source of the electric signals unless the increase in bulk resistivity occurs broadly in the observation field. Variation of the zeta potential according to the deformation stage makes it difficult to interpret the self-potential data quantitatively. Results of the present experiments, however, indicate the zeta potential does not vary so much throughout all the deformation stage of the rock up to failure.

\section{Acknowledgments}

The authors thank the Editor T. Ishido and the anonymous reviewers for constructive comments which greatly improved the paper. This paper was partially supported by JSPS KAKENHI(05J11788).

\section{References}

[1] R. F. Corwin and D. B. Hoover, "Self-potential method in geothermal-exploration," Geophysics, vol. 44, no. 2, pp. 226245, 1979.

[2] T. Ishido, H. Mizutani, and K. Baba, "Streaming potential observations, using geothermal wells and in situ electrokinetic coupling coefficients under high temperature," Tectonophysics, vol. 91, no. 1-2, pp. 89-104, 1983.

[3] T. Ishido, T. Kikuchi, N. Matsushima et al., "Repeated selfpotential profiling of izu-oshima volcano, Japan," Journal of Geomagnetism and Geoelectricity, vol. 49, no. 11-12, pp. 12671278, 1997.

[4] J. Zlotnicki, Y. Sasai, P. Yvetot et al., "Resistivity and selfpotential changes associated with volcanic activity: the July 8, 2000 Miyake-jima eruption (Japan)," Earth and Planetary Science Letters, vol. 205, no. 3-4, pp. 139-154, 2003.

[5] H. Hase, T. Ishido, S. Takakura, T. Hashimoto, K. Sato, and Y. Tanaka, "Zeta potential measurement of volcanic rocks from Aso caldera," Geophysical Research Letters, vol. 30, no. 23, pp. 2-4, 2003.

[6] K. Aizawa, "A large self-potential anomaly and its changes on the quiet Mt. Fuji, Japan," Geophysical Research Letters, vol. 31, no. 5, article L05612, p. 4, 2004.

[7] F. Perrier, M. Trique, B. Lorne, J. P. Avouac, S. Hautot, and P. Tarits, "Electric potential variations associated with yearly lake level variations," Geophysical Research Letters, vol. 25, no. 10, pp. 1955-1958, 1998.

[8] M. Trique, F. Perrier, T. Froidefond, J. P. Avouac, and S. Hautot, "Fluid flow near reservoir lakes inferred from the spatial and temporal analysis of the electric potential," Journal of Geophysical Research B, vol. 107, no. 10, pp. 1-28, 2002.

[9] W. R. Sill, "Self-potential modeling from primary flows," Geophysics, vol. 48, no. 1, pp. 76-86, 1983.

[10] T. Ishido and J. W. Pritchett, "Numerical simulation of electrokinetic potentials associated with subsurface fluid flow," Journal of Geophysical Research B, vol. 104, no. 7, pp. 1524715259, 1999.

[11] A. Revil, H. Schwaeger, L. M. Cathles, and P. D. Manhardt, "Streaming potential in porous media 2. Theory and application to geothermal systems," Journal of Geophysical Research B, vol. 104, no. 9, pp. 20033-20048, 1999.

[12] S. R. Pride, F. Moreau, and P. Gavrilenko, "Mechanical and electrical response due to fluid-pressure equilibration following an earthquake," Journal of Geophysical Research B, vol. 109, no. 3, article B03302, p. 10, 2004.

[13] M. R. Sheffer and D. W. Oldenburg, "Three-dimensional modelling of streaming potential," Geophysical Journal International, vol. 169, no. 3, pp. 839-848, 2007.

[14] H. Mizutani, T. Ishido, T. Yokokura, and S. Ohnishi, "Electrokinetic phenomena associated with earthquakes," Geophysical Research Letters, vol. 3, no. 7, pp. 365-368, 1976.

[15] A. Nur, "Dilatancy, pore fluids, and premonitory variations of $\mathrm{T}_{s}-\mathrm{T}_{p}$ travel times," Bulletin of the Seismological Society of America, vol. 62, no. 5, pp. 1217-1222, 1972.

[16] C. H. Scholz, L. R. Sykes, and Y. P. Aggarwal, "Earthquake prediction: a physical basis," Science, vol. 181, no. 4102, pp. 803-810, 1973. 
[17] T. Ishido, "Experimental and theoretical basis of electrokinetic phenomena in rock-water systems and its applications to geophysics," Journal of Geophysical Research, vol. 86, no. 3, pp. 1763-1775, 1981.

[18] F. D. Morgan, E. R. Williams, and T. R. Madden, "Streaming potential properties of Westerly granite with applications," Journal of Geophysical Research, vol. 94, no. 9, pp. 1244912461, 1989.

[19] L. Jouniaux and J. P. Pozzi, "Permeability dependence of streaming potential in rocks for various fluid conductivities," Geophysical Research Letters, vol. 22, no. 4, pp. 485-488, 1995.

[20] B. Lorne, F. Perrier, and J. P. Avouac, "Streaming potential measurements: 1. Properties of the electrical double layer from crushed rock samples," Journal of Geophysical Research B, vol. 104, no. 8, pp. 17857-17877, 1999.

[21] F. Perrier and T. Froidefond, "Electrical conductivity and streaming potential coefficient in a moderately alkaline lava series," Earth and Planetary Science Letters, vol. 210, no. 1-2, pp. 351-363, 2003.

[22] L. Jouniaux, S. Lallemant, and J. P. Pozzi, "Changes in the permeability, streaming potential and resistivity of a claystone from the Nankai prism under stress," Geophysical Research Letters, vol. 21, no. 2, pp. 149-152, 1994.

[23] L. Jouniaux and J. P. Pozzi, "Streaming potential and permeability of saturated sandstones under triaxial stress: consequences for electrotelluric anomalies prior to earthquakes," Journal of Geophysical Research, vol. 100, no. 6, pp. 1019710209, 1995.

[24] S. Yoshida, O. C. Clint, and P. R. Sammonds, "Electric potential changes prior to shear fracture in dry and saturated rocks," Geophysical Research Letters, vol. 25, no. 10, pp. 1577-1580, 1998.

[25] B. Lorne, F. Perrier, and J. P. Avouac, "Streaming potential measurements 2. Relationship between electrical and hydraulic flow patterns from rock samples during deformation," Journal of Geophysical Research B, vol. 104, no. 8, pp. 17879-17896, 1999.

[26] L. Jouniaux, M. L. Bernard, M. Zamora, and J. P. Pozzi, "Streaming potential in volcanic rocks from Mount Pelée," Journal of Geophysical Research B, vol. 105, no. 4, pp. 83918401, 2000.

[27] S. Yoshida, "Convection current generated prior to rupture in saturated rocks," Journal of Geophysical Research B, vol. 106, no. 2, pp. 2103-2120, 2001.

[28] P. M. Reppert and F. D. Morgan, "Temperature-dependent streaming potentials: 2. Laboratory," Journal of Geophysical Research B, vol. 108, no. 11, pp. 4-13, 2003.

[29] T. Tosha, N. Matsushima, and T. Ishido, "Zeta potential measured for an intact granite sample at temperatures to $200^{\circ}$ C," Geophysical Research Letters, vol. 30, no. 6, pp. 28-1, 2003.

[30] S. R. de Groot and P. Mazur, Non-Equilibrium Thermodynamics, North-Holland, Amsterdam, The Netherlands; Interscience Publishers, New York, NY, USA, 1962.

[31] S. Pride, "Governing equations for the coupled electromagnetics and acoustics of porous media," Physical Review B, vol. 50, no. 21, pp. 15678-15696, 1994.

[32] J. B. Walsh and W. F. Brace, "The effect of pressure on porosity and the transport properties of rock," Journal of Geophysical Research, vol. 89, no. 11, pp. 9425-9431, 1984.

[33] O. Nishizawa, "New multi-wire type and co-axial type feedthroughs for an oil pressure medium vessel," Bulletin of the Geological Survey of Japan, vol. 48, pp. 431-438, 1997.
[34] T. Ishido and O. Nishizawa, "Effects of Zeta potential on microcrack growth in rock under relatively low uniaxial compression," Journal of Geophysical Research, vol. 89, no. 6, pp. 4153-4159, 1984.

[35] M. Takahashi, "Permeability change during experimental fault smearing," Journal of Geophysical Research B, vol. 108, no. 5, pp. 1-15, 2003.

[36] R. L. Kranz, J. S. Saltzman, and J. D. Blacic, "Hydraulic diffusivity measurements on laboratory rock samples using an oscillating pore pressure method," International Journal of Rock Mechanics and Mining Sciences, vol. 27, no. 5, pp. 345352, 1990.

[37] G. J. Fischer, "The determination of permeability and storage capasity: pore pressure oscillation method," in Fault Mechanics and Transport Properties of Rocks, B. Evan and T. F. Wong, Eds., pp. 187-211, Academic Press, San Diego, Calif, USA, 1992.

[38] G. J. Fischer and M. S. Paterson, "Measurement of permeability and storage capacity in rocks during deformation at high temoerature and pressure," in Fault Mechanics and Transport Properties of Rocks, B. Evan and T. F. Wong, Eds., pp. 213-252, Academic Press, San Diego, Calif, USA, 1992.

[39] I. Song and J. Renner, "Analysis of oscillatory fluid flow through rock samples," Geophysical Journal International, vol. 170, no. 1, pp. 195-204, 2007.

[40] R. G. Packard, "Streaming potentials across glass capillaries for sinusoidal pressure," The Journal of Chemical Physics, vol. 21, no. 2, pp. 303-307, 1953.

[41] P. M. Reppert, F. D. Morgan, D. P. Lesmes, and L. Jouniaux, "Frequency-dependent streaming potentials," Journal of Colloid and Interface Science, vol. 234, no. 1, pp. 194-203, 2001.

[42] P. M. Reppert and F. D. Morgan, "Streaming potential collection and data processing techniques," Journal of Colloid and Interface Science, vol. 233, no. 2, pp. 348-355, 2001.

[43] W. F. Brace, J. B. Walsh, and W. T. Frangos, "Permeability of granite under high pressure," Journal of Geophysical Research, vol. 73, no. 6, pp. 2225-2236, 1968.

[44] Y. Bernabé, U. Mok, and B. Evans, "Permeability-porosity relationships in rocks subjected to various evolution processes," Pure and Applied Geophysics, vol. 160, no. 5-6, pp. 937-960, 2003.

[45] W. Zhu, L. G. J. Montési, and T. F. Wong, "A probabilistic damage model of stress-induced permeability anisotropy during cataclastic flow," Journal of Geophysical Research B, vol. 112, no. 10, Article ID B10207, 2007.

[46] X. Guichet, L. Jouniaux, and J. P. Pozzi, "Streaming potential of a sand column in partial saturation conditions," Journal of Geophysical Research B, vol. 108, no. 3, article 2141, p. 12, 2003.

[47] N. Linde and A. Revil, "Inverting self-potential data for redox potentials of contaminant plumes," Geophysical Research Letters, vol. 34, no. 14, Article ID L14302, 2007.

[48] A. Revil, N. Linde, A. Cerepi, D. Jougnot, S. Matthäi, and S. Finsterle, "Electrokinetic coupling in unsaturated porous media," Journal of Colloid and Interface Science, vol. 313, no. 1, pp. 315-327, 2007.

[49] T. Ishido, "Electrokinetic mechanisms for the "W"-shaped self-potential profile on volcanoes," Geophysical Research Letters, vol. 31, no. 15, article L15616, p. 5, 2004.

[50] S. Onizawa, N. Matsushima, T. Ishido, H. Hase, S. Takakura, and Y. Nishi, "Self-potential distribution on active volcano controlled by three-dimensional resistivity structure in IzuOshima, Japan," Geophysical Journal International, vol. 178, no. 2, pp. 1164-1181, 2009. 

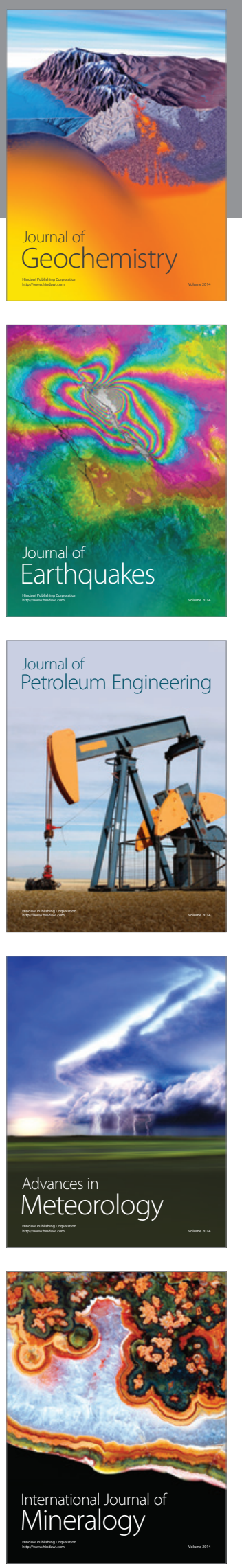
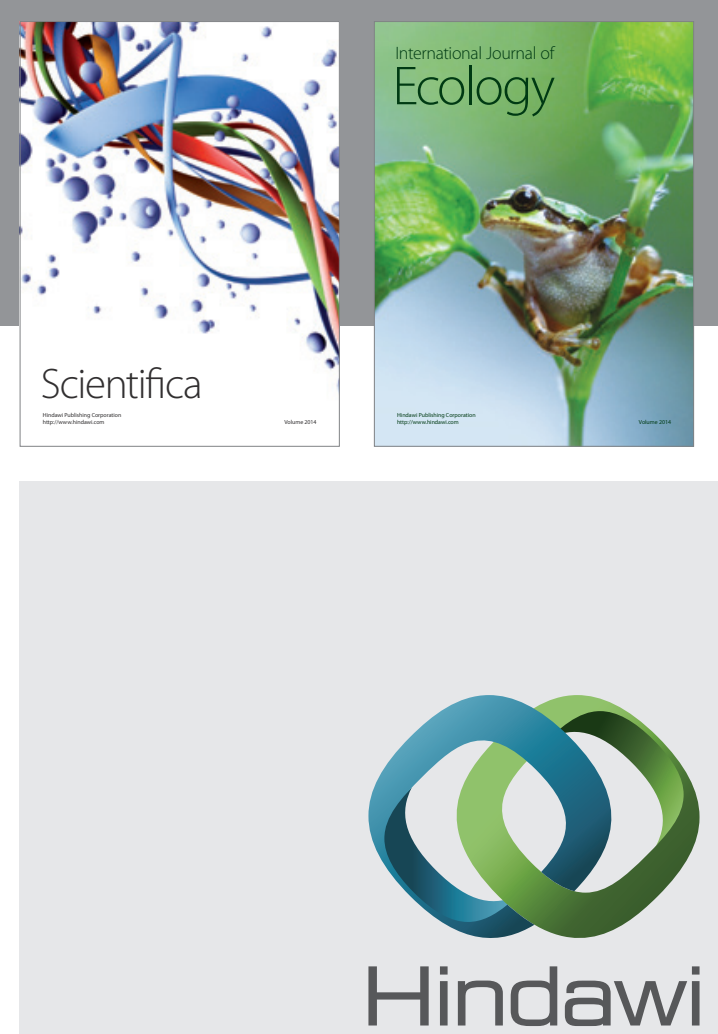

Submit your manuscripts at http://www.hindawi.com
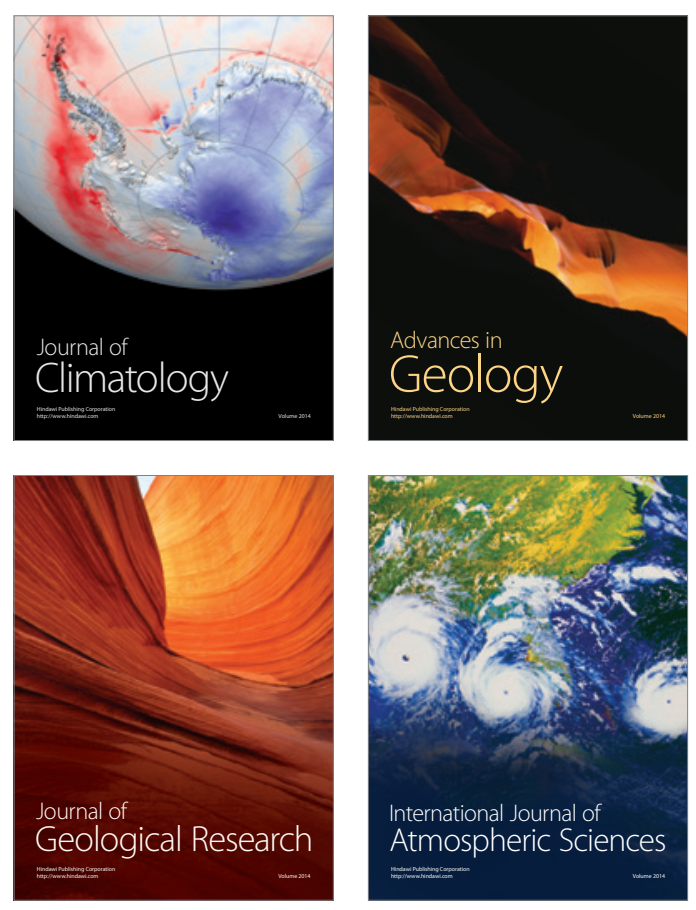
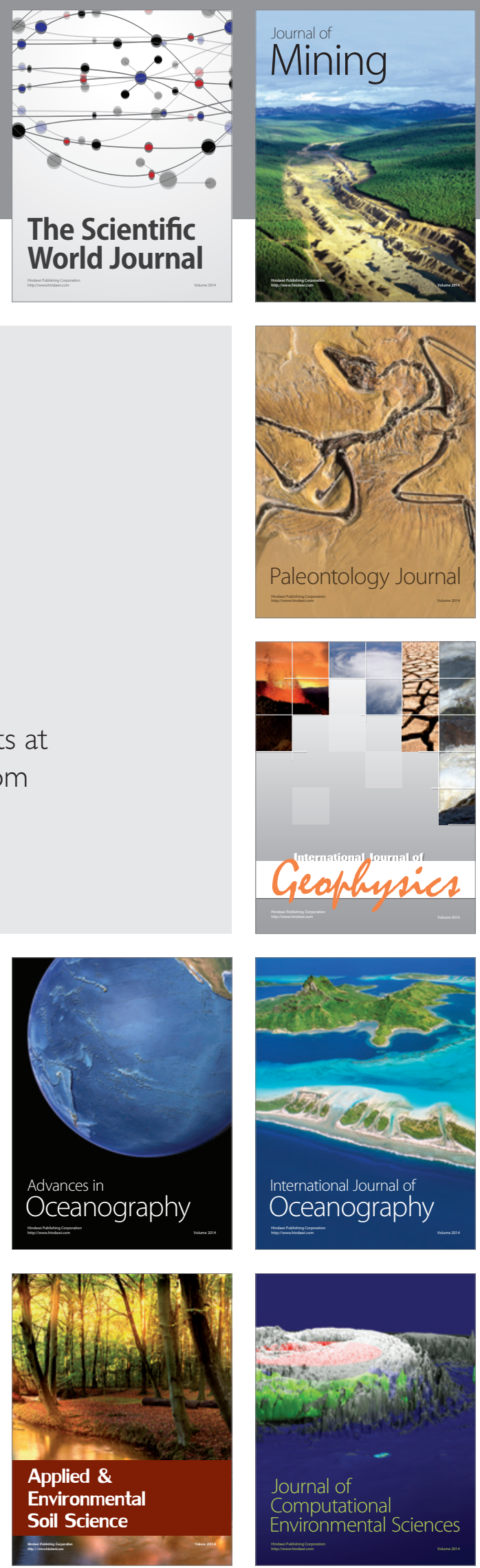